\title{
Erratum to: An international position paper on mother-infant (perinatal) mental health, with guidelines for clinical practice
}

Ian Brockington $^{1} \cdot$ Ruth Butterworth $^{1} \cdot$ Nine Glangeaud-Freudenthal $^{2}$

Published online: 6 December 2016

(C) Springer-Verlag Wien 2016

Erratum to: Arch Womens Ment Health

DOI:10.1007/s00737-016-0684-7

In the paragraph headed 'Postscript', three of the author names are wrongly spelt. The names of the authors should be: Luc Turmes, Kwok-hung Ku, and Saralee Glasser.

The online version of the original article can be found at: http://dx.doi. org/10.1007/s00737-016-0684-7

$\triangle$ Ian Brockington

i.f.brockington@bham.ac.uk

1 University of Birmingham, Edgbaston, Birmingham B15 2TT, UK

2 Inserm U 1153, Paris Descartes University, Paris, France 